\title{
PARENTAL INFLUENCE ON DRUG AND SUBSTANCE ABUSE AMONG SECONDARY SCHOOL STUDENTS IN KINANGO SUB-COUNTY, KENYA
}

\author{
Misango Nathan Chapia ${ }^{i}$, \\ Mwaura Kimani, \\ Naftali Rop \\ School of Education, \\ Maasai Mara University, \\ Kenya
}

\section{Abstract:}

The United Nations office on Drug and Crime estimates that 200 million people worldwide abuse drugs. Africa is a major supplier of drugs such as cannabis and cocaine which are the most widely abused. Large hauls of cannabis and cocaine have been discovered in East African region. In Kenya, findings show that drug and substance abuse is a major social problem. A report of survey on drug and substance abuse by NACADA, revealed that $32.4 \%$ of people aged between $18-28$ years have consumed alcohol or other type of drugs and substances. Majority of secondary school students are in the age bracket 14-22 years, the group that is most affected. Drug and substance abuse is partly responsible for the riots, strikes, destruction and burning of property in secondary schools. The prevalence rate of drug abuse in Kinango Sub-County was 20.3\%. The purpose of the study was to investigate parental influence on Drug and Substance Abuse among Secondary School Students in Kinango Sub-County Kwale County. Erickson's theory on social development and Bandura's Social Learning Theory (SLT) helped in explaining the findings of the study. A survey research design was employed for the study with the study population comprising of all secondary school students, heads of guidance and counselling departments and deputy principals in Kinango subcounty totalling 4,964 people. Four public secondary schools were selected through stratified random sampling. The sample size comprised of 4 deputy principals, 4 heads of guidance and counselling departments of the selected schools and 384 students selected by random sampling. Data was collected through questionnaires and an interview schedule. Validity of the instruments was ensured by using expert judgement of my supervisors. A mixed research methodology was used during data presentation where both descriptive and inferential statistics were used to make inferences and draw conclusions. This was done with help of SPSS version 23. The overall reliability of all the instruments had Cronbach's alpha of 0.842 which was above the minimum threshold of

${ }^{i}$ Correspondence: email nathanchapia@gmail.com 
0.7. Validity was determined by; the Kaiser- Meyer-Olkim (KMO) Measures of Sampling Adequacy and Bartlett's Test of Sphericity. Values of 0.787 and 0.000 were obtained respectively, which are acceptable indexes. It was established that there is statistically significant influence of parental influence on drug and substance abuse among secondary school students in Kinango sub-County from hypothesis one $(\mathrm{p}<0.05)$. The study recommended that parents should abstain from drugs because they are role models of their children and that guidance and counselling should be strengthen in schools.

Keywords: parental influence, drugs, substance abuse, secondary school

\section{Introduction}

The United Nations Office on Drug and Crime estimates that 200 million people worldwide abuse drugs (Nations \& Crime, 2010). This was an equivalent of $5 \%$ of the global population but now the number of those who abuse drugs could be high. Consequently, the percentage of those who abuse drugs could be much greater. According to UNODC, the global problem continues to spread in geographical terms as more countries reported increases rather than decreases in illicit drug consumption and abuse, this is a worrying trend. The most widely abused illicit substances worldwide are cannabis consumed by an estimated 160 million people, followed by the AmphetamineType Stimulants (ATS) consumed by around 34 million people, according to estimates provided by UNODC (Nations \& Crime, 2010). These figures could definitely be much high now.

In one of European School Survey project, on alcohol and other Drugs, it was found that more than half of 15 - 16 year old British teenagers admitted 'binge drinking'. Under -16 s are drinking as twice as much as they were ten years ago (Arif \& Rohrer, 2005). Among 16-24 year olds, $38 \%$ of men and $21 \%$ of women regularly drink twice, the recommended daily limit (Gross, 2016). That kind of drinking is bad for one's health leave along the economic and social implications. Every country, developed or developing, incurs significant costs as a result of damages caused by alcohol or drug and substance abuse (Nations \& Crime, 2010). Many accidents on our roads are caused by drunk drivers or drivers who are under the influence of some drug. Serious mistakes are made in hospitals and industries by workers who are under the influence of drugs. According to the World Health Organization (WHO), a third of the world population above the age of 15 years, use tobacco in the form of cigarettes. This translates to approximately 1.1 billion people, 800 million of these are males and 300 million are females. 700 million out of the 800 million males, live in developing countries (Organization, 2014).

Despite eradication efforts in countries in Africa, the region still remains a major supplier of some drugs such as cannabis, which is one of the most widely abused drugs. Africa has been experiencing an escalating problem with drug abuse and trafficking since the early nineteen eighties. Data collected under the Eastern Africa Drug Information System / Global Assessment Programme (EADIS/GAP), country mission reports coupled 
with small-scaled research activities conducted by governmental organizations all attest to this, although reliable information is scarce (Dahoma et al., 2006). Africa's role in the global drugs supply chain is increasing. Already the continent is the second largest region for cannabis production, trafficking and consumption, accounting for $26 \%$ of global seizures of this drug in 2001 (Nations \& Crime, 2010). By country, the largest hauls in this period were in Kenya, Nigeria, and the Republic of South Africa, while Morocco is said to be one of the main producers of cannabis resin. East African region has become a fall back for drug dealers. This is mainly because there is increased control of traditional routes, for example, through Netherlands and Spain (Nations \& Crime, 2010). Cocaine worth 6.4 billion Kenya shillings was intercepted in Malindi and Nairobi on December 14, 2004 (Maithya, 2009).

Kenya is one of the developing countries in Africa that has lately been experiencing rapid increase in production, distribution and consumption of multiple drugs of dependence (Syvertsen et al., 2016); (David M. Ndetei MBChB, Lincoln I. Khasakhala MBChB, BA, Francisca A. Ongecha-Owuor MBChB, \& Donald A. Kokonya MBChB, 2009); (Dept, WHO Initial Consultation Group Meeting on Preparation of a Basic Manual on Substance Abuse Epidemiology (1992: Geneva, \& Meeting on the Consolidated Epidemiological Manual on Substance Abuse (1994: Athens, 2000); (Beckerleg, 2006). A heroin haul estimated to be worth 25 billion shillings seized by the Australian Navy off the Kenya Coast, is by far the biggest found in Africa (Dimova, 2016). In his determination to fight drug abuse, the president of the republic of Kenya, Mr. Uhuru Kenyatta ordered the blowing up of a ship carrying $373.8 \mathrm{~kg}$ of heroin worth1.3 billion shillings off Mombasa (Syvertsen et al., 2016). There is intense global concern about the problem of drug abuse. Therefore, every nation, including Kenya, must take a firm stand in combating all aspects of drug and substance abuse. United Nations Drug Control Programme (UNDCP) was created by the United Nation general assembly based on the recognition of the need for an organization that would foster concerted international action against illicit drug production, trafficking and abuse. The formation of UNDCP was evidence of the determination of the governments of the world, working through the United Nations to put an end to the problem of drug and substance abuse. In order to comply with UN, the government of Kenya has ratified two major United Nations Conventions on narcotic drugs and psychotropic substances in its quest to protect its citizens from the ravages of the global drug abuse menace. Kenya government enacted a new anti-drug law in 1994, the Narcotics and Psychotropic Substances Control Act. In addition, Kenya Anti-Narcotic Unit was simultaneously formed.

In response to global warnings on the dangers posed by drug abuse, the National Agency for Campaign Against Drug Abuse (Nacada) has been pushing for the establishment of a national drug control authority to enforce all drug trafficking laws in Kenya (Cheloti \& Gathumbi, 2016). According to Kaguthi, Nacada drugs and are likely to destroy their lives before they become adults. He argues that most secondary school students today are experimenting with drugs. 
The government of Kenya established the National Authority for the Campaign against Drug Abuse, in 2012. The functions of the Authority include: Carrying out public education on alcohol and drug abuse directly and in collaboration with other public or private bodies and institutions; facilitate public participation in the control of alcohol and drug abuse. The agency is now in a better position to wage war against drug and substance abuse (Marais \& Maithya, 2015). Findings from a rapid assessment survey revealed that drug and substance abuse was a major social problem in Kenya (The History of NACADA, 2009). According to the Rapid assessment survey, $22 \%$ of all respondents aged between 15-65 years were current users of at least one substance of abuse albeit with huge variations based on gender and rural/urban population. The current users of cigarettes and miraa were $11 \%$ and $6 \%$ respectively. For sniffed /chewed tobacco products and bhang; the proportions for current use were $2 \%$ and $1 \%$ respectively. The survey revealed that $64 \%$ of men were leading drug-free lives compared to $91 \%$ of women respondents (The History of NACADA, 2009).

According to the Report of Survey on Drugs and Substance Abuse in Coast province, Kenya, Mombasa had the highest proportion of persons currently consuming alcohol or other drugs with $29.5 \%$ followed by Malindi with $27 \%$ and Lamu was ranked third with $23.7 \%$ of its population consuming alcohol and other types of drugs. In Kwale the prevalence rate of alcohol and drug use is 20.3\% (Kinoti, Jason, \& Harper, 2011). Kinango Sub-County is in Kwale County; therefore, the prevalence rate of drug and substance abuse is $20.3 \%$ (NACADA, 2012). These were general results for people aged between 15-65 years in Kwale County. A prevalence rate of 20.3\% is quite high and calls for concern. However, the results were not specifically for secondary school students whose ages range between 14-24 years. In another report it was observed that drugs and substance abuse, both licit and illicit are forming a sub-culture in Kenya among the students (NACADA 2007). It was against this background that the study was undertaken to investigate certain selected factors to find out how they predisposed secondary school students to drug and substance abuse in Kinango Sub-County, Kwale.

\section{Research Objective}

To establish the parental influence on drug and substance abuse among secondary school students in Kinango Sub-County.

\section{Research Hypothesis}

There is no statistically significant influence of Parental influence on drug and substance abuse among secondary school students in Kinango Sub-County. 


\section{Literature Review}

\subsection{Drugs and Drug Abuse}

A substance is considered abused if it is deliberately used to induce physiological or psychological effects or both for purposes other than therapeutic ones and when its use contributes to health risks, disruption of physiological functioning, adverse social consequences or some combination of these. Drugs may be prescribed for the specific therapeutic purposes, but the same drugs may be abused by obtaining and taking them without prescription for the purpose of experiencing some wanted side effects. Not all abused chemicals are drugs. Abused substances other than drugs include; glue, cleaning fluids, petrol and other chemicals that can cause psychological and physiological effects. Drug and substance abuse among adolescents is a major public health problem and has been linked to such adverse consequences as car crashes, suicide, delinquency, criminal behaviours, and psychological difficulties. The presence of drug and substance abuse problems during adolescence is the single most predictive factor for adult drug dependence (Gross, 2016). In secondary schools, discipline problems include all forms of disrespect, unruly behaviour, use of bad/ vulgar language, smoking, drinking alcohol, robbery, stealing school property gambling and bullying (Nyaga, 2004). Nyaga concentrated on discipline matters, although he mentions smoking and drinking of alcohol, he does not deal with the predisposing factors towards smoking and alcohol drinking. In Kenya maladjusted students exhibit numerous indiscipline symptoms like aggression, shyness, suspicion, tattling, bullying, cruelty, cheating, truancy, tardiness, stealing, profanity, boisterousness and all sorts of disorderliness (Nyaga, 2004). Again, in his study, Nyaga is concerned with indiscipline in secondary school, but not predisposing factors to drug and substance abuse.

A more recent study by Karega showed that the more commonly occurring behaviour problems in schools are: boy/ girl relationship, poor response to bells, theft, faking sickness, fighting, noise making and destruction of property, refusal to complete assignments as well as riots and demonstrations were the most frequently cited indiscipline problems (Karega, 2012). In another research it was found that lateness, absenteeism, truancy, unattended duties, and wrong dressing and smoking were the commonly reported behaviour problems (Mutisya, 2008). These studies majored on behaviour problems in general whereas this study will specifically deal with selected factors predisposing secondary school students in Kinango Sub-County, Kwale County, Kenya. In a recent study on perceived factors influencing deviant behaviour among the youth in Njathaini community, Nairobi, Kenya, it was reported that the most common forms of deviant behaviour were alcohol and drug abuse, premarital sex, prostitution, gang fighting and rape. The study targeted 395 youth aged between 15-35 years and used purposive sampling to ensure gender balance and was carried out in a slum located in Nairobi (Mbuthia, 2013). Although Mbuthia mentions drug and substance abuse he does not deal with predisposing factors. Mbuthia did not specifically research on secondary school students but youth in general. He used purposive sampling technique to collect 
his data. In Contrast, in this study, simple random sampling technique was used to select the students in each of the schools, stratified random technique was applied to select the schools to participate in the research and finally purposive sampling technique was used to select the guidance and counselling teachers as well as the deputy principals to be interviewed. Although the two studies are somehow related, different research designs were used.

\subsection{Parental Influence on Drug and Substance Abuse}

Drug and substance abuse by young people, and problems associated with this behaviour have been part of human history. What is different today is increased availability of a wide variety of substances and the declining age at which experimentation with these substances take place (Nations \& Crime, 2010). Drug abuse affects the children of the rich as well as those from poor families (Bahr, Hoffmann, \& Yang, 2005). Drug abuse is caused by a combination of environmental, biological and psychological factors (Shoemaker, 2010). There are various factors that cause young people to abuse drugs and even become addicted (Schaefer, Vito, Marcum, Higgins, \& Ricketts, 2015); (Muigai, 2012). These include family networks, interactions and home environments. Adolescents with substance abusing parents experience a higher rate of parental problems than do adolescents whose parents do not abuse substances (Muigai, 2012). This may cause poor parent-child attachment, which may in turn lead to a lack of commitment to conventional activities thereby at times leading to adolescent drug taking. These findings show how drug and substance abuse affect adolescents. However, they do not reveal how secondary school students were exposed to drugs before they started abusing them. There was therefore a need to find out how certain factors predisposed secondary school students to drug and substance abuse. This study investigated how parental influence could predispose secondary school students to drug and substance abuse.

In another study it was found that youths with poor home support tend to seek support and understanding elsewhere. Many find this affection, understanding and support in the lifestyle of a drug abusing subgroup (Weinberg, Rahdert, Colliver, \& Glantz, 1998). The concepts of family and self-identity are certainly closely related. Interactions within the family unit play a major role in the adolescent's personality or self- concept formation. In addition, the exposure to cultural norms through the family, as well as individual adaptations, lays the foundation for influential modelling and acceptance of social orientations. The family was often viewed as the basic source of strength, nurturing and supporting its members, as well as ensuring stability and generational continuity for the community and its culture (Kandel, Kessler, \& Margulies, 1978). From the traditional point of view, it was the duty of the family to protect and sustain both strong and weak members, helping them to deal with stress while nurturing its younger and more vulnerable members, the children.

Families can have a powerful influence on shaping the attitudes, values, and behaviour of children (Maithya, 2009). During socialization, parents and family members direct young people's conduct along desired channels, and in so doing succeed in 
enforcing conformity to social norms. In traditional African society, socialization began with the birth of a child and progressed in stages to old age, building on preceding socially recognized achievements. Socialization involved being taught all the things one needed to know in a particular context. The child was integrated into the community by being taught discipline, social roles and skills so that he/she became part of the family. The child would feel that he/ she was needed, wanted and depended upon. In such setting socialization was often not planned; children learnt from watching and imitating what adults said and did. As they grew, they were likely to pick up both positive and negative habits from their parents.

The environment in which children grew up played a great role in shaping their character (Maithya, 2009). The claim was that children socialized in the bar culture by their parents during family entertainments would tend towards use of alcohol later in life. This would impact negatively on the development of the children in the long term. It was difficult for parents to sensitize their children about the dangers of alcohol consumption when they spend long hours imbibing in the company of the very people whose character they were expected to mould. Although Maithya's study was not about predisposing factors, it is clear from his study that parental influence is a predisposing factor to drug abuse. Due to the church and interaction with different people, secondary school students are acquiring values that go beyond those of their immediate localized culture (Maithya, 2009). Therefore, the family is becoming less involved in socialization of the young, very little is communicated to the young in the way of values and customs. As a result, the traditional value system has been eroded leading to moral decadence. In school, children spend most of their time with the peer group. However, peers have a high degree of influence only when parents have abdicated their traditional supervisory roles (Blum, 1972). Hence, active and involved parents may be able to limit the influence of peer groups on young people attitudes towards drug use, and therefore be crucial influence on children's behaviour. Generally, parents are role models for their children. Nacada carried out a survey in 2012 covering all the counties in Kenya. In their survey they found out that about $7.2 \%$ of the children who have ever taken alcohol have either, father, mother or close relative using one drug or the other. These findings are a generalization from 47 counties and therefore may not be specific to secondary school students. This study sought to find out the effect of parental influence on drug and substance abuse among secondary school students in Kinango sub county, Kwale.

Poor parenting is linked to alcohol abuse as well as abuse of other substances. In a study of 542 middle school students from the Birmingham Youth Violence Study in Alabama, USA, poor parenting practices (e.g. less nurturance and harsh and inconsistent discipline) was found to be strongly related to school- level alcohol and cigarette use (Mrug, Gains, Su \& Windle 2010 ) they concluded in line with earlier studies that poor parenting could increase susceptibility to school- level substance use through greater deviant affiliations or impaired ability to withstand negative peer influence (Mrug \& Windle, 2009; Simons-Morton, 2002). Although parental guidance in parenting is the norm, peer guidance and approval become increasingly powerful and valued during the 
period of adolescence. Rather than seeking parental guidance, they often seek role models outside the family who may be characters or personalities. Nonetheless, these shifts in influences shape numerous aspects of adolescents' behaviour, including ADA (Wills, Sandy \& Yaeger, 2001). Family variables still continue to exert a strong influence not only because most adolescents continue to value their family members as models of behaviour, but also because these factors encompass such a wide range of influences. Therefore, parental influence is a significant predisposing factor to adolescent drug abuse that deserves to be studied.

\section{Research Methodology}

A survey research design was employed for the study with the study population comprising of all secondary school students, heads of guidance and counselling departments and deputy principals in Kinango sub-county totalling 4,964 people. Four public secondary schools were selected through stratified random sampling. The sample size comprised of 4 deputy principals, 4 heads of guidance and counselling departments of the selected schools and 384 students selected by random sampling. Data was collected through questionnaires and an interview schedule. Validity of the instruments was ensured by using expert judgement of my supervisors. A mixed research methodology was used during data presentation where both descriptive and inferential statistics were used to make inferences and draw conclusions. This was done with help of SPSS version 23. The overall reliability of all the instruments had Cronbach's alpha of 0.842 which was above the minimum threshold of 0.7. Validity was determined by; the Kaiser-MeyerOlkim (KMO) Measures of Sampling Adequacy and Bartlett's Test of Sphericity. Values of 0.787 and 0.000 were obtained respectively, which are acceptable indexes.

\section{Results and Discussion}

\subsection{Qualitative Data and Analysis}

Table 1: Father drug abuse vs student drug abuse

\begin{tabular}{|l|l|c|}
\hline \multicolumn{2}{|l|}{} & \% of students who do the same \\
\hline \multirow{2}{*}{$\begin{array}{l}\text { Dathers } \\
\text { Abuse }\end{array}$} & Smoke cigarettes & 10.17 \\
\cline { 2 - 3 } & Does not smoke & 3.26 \\
\cline { 2 - 3 } & Drink alcohol & 19.10 \\
\cline { 2 - 3 } & Does not drink alcohol & 3.32 \\
\cline { 2 - 3 } & Chew miraa & 25.45 \\
\cline { 2 - 3 } & Does not chew miraa & 3.70 \\
\hline
\end{tabular}

From Table 1, the percentage of students whose fathers abuse drugs and who also abuse drug is high than the percentage of those whose fathers do not abuse. 


\begin{tabular}{|l|c|c|}
\hline \multicolumn{2}{|c|}{ Table 2: Mother drug abuse vs student drug abuse } \\
\hline \multicolumn{2}{|c|}{} & \% of students who abuse drug \\
\hline \multirow{2}{*}{$\begin{array}{l}\text { Mother } \\
\text { drug }\end{array}$ abuse } & Smoke cigarettes & 7.02 \\
\cline { 2 - 3 } & Does not smoke & 4.54 \\
\cline { 2 - 3 } & Drink alcohol & 8.16 \\
\cline { 2 - 3 } & Does not drink alcohol & 7.07 \\
\cline { 2 - 3 } & Chew miraa & 10.42 \\
\cline { 2 - 3 } & Does not chew miraa & 6.50 \\
\hline
\end{tabular}

From Table 2, the percentage of students whose mothers abuse drugs and who also abuse drug is high than the percentage of those whose mothers do not abuse.

\subsection{Parental Influence on Drug and Substance Abuse among Secondary School Students.}

From Table 3 the null hypothesis should be rejected wherever the $\mathrm{p}$ value is less than 0.05 the specified level of significance. From the results in Table 3 the p value is .000 which is less than 0.05 the set level of significance. Therefore, the null hypothesis which stated that there is no statistically significant influence of parental influence on drug and substance abuse among secondary school students in Kinango Sub County, was rejected. The alternative hypothesis was accepted. Therefore, it can be concluded that there is statistically significant influence of parental influence on drug and substance abuse among secondary school students in Kinango Sub County.

Table 3: Regression Coefficients ${ }^{\mathrm{a}}$

\begin{tabular}{|c|c|c|c|c|c|}
\hline \multirow[t]{2}{*}{ Model } & \multicolumn{2}{|c|}{ Unstandardized Coefficients } & \multirow{2}{*}{$\begin{array}{c}\text { Standardized Coefficients } \\
\text { Beta }\end{array}$} & \multirow[t]{2}{*}{$t$ test } & \multirow[t]{2}{*}{ Sig. } \\
\hline & B & Std. Error & & & \\
\hline (Constant) & .590 & .119 & & 4.971 & .000 \\
\hline Parent al Influence & .506 & .041 & .540 & 12.333 & .000 \\
\hline
\end{tabular}

a. Dependent Variable: Student drug usage

The percentages of students who abuse drugs from two categories of parents were determined and compared. The results generally indicated that the percentage of students who abuse drugs and whose parents abuse drugs is greater than the percentage of those who abuse drugs and whose parents do not abuse drugs. From the tested hypothesis it was established that there is a statistically significant influence of parental influence on drug and substance abuse among secondary school students in Kinango Sub-County. These findings were in agreement with Nacada 2012 survey whose findings showed that $7.2 \%$ of the children who have taken drugs have a parent who takes one drug or another (Nacada, 2012). Similarly, they also agree with the study by Willis, Sandy and Yaeger whose findings revealed that the family has strong influence on the adolescents (Willis, Sandy and Yaeger, 2001). The findings of this study also agree with Muigai's study whose findings showed that adolescents with substance abusing parents have a higher rate of drug abuse (Muigai, 2012). 


\section{Conclusion}

The study concluded that there is statistically significant influence of parental influence on drug and substance abuse among secondary school students in Kinango Sub-County. This implies that those students whose parents' abuse drugs are more likely to abuse drugs compared to the ones whose parents do not abuse drugs.

\section{Recommendations}

Parents should be made aware that they are role models to their children and therefore should abstain from drugs if they want their children to avoid the same. Under no circumstances, should parent abuse drugs in front of their children.

\section{Conflict of Interest Statement}

The authors declare no conflicts of interests.

\section{About the Authors}

Misango Nathan Chapia is a Master's Degree student in Guidance and Counselling at Maasai Mara University, Kenya.

Dr. Mwaura Kimani is a Lecturer in Psychology at the School of Education Maasai Mara University, Kenya. He has vast experience in qualitative and quantitative research in educational Statistics, measurement and evaluation. He has long university teaching experience and Student supervision.

Dr. Naftali Rop is a Lecturer in Special Needs Education in the Educational Foundation \& Psychology Department at the School of Education Maasai Mara University, Kenya.

\section{References}

\section{a. Journal articles}

Arif, A. A., \& Rohrer, J. E. (2005). Patterns of alcohol drinking and its association with obesity: data from the third national health and nutrition examination survey, 1988-1994. BMC Public Health, 5, 126. https://doi.org/10.1186/1471-2458-5-126

Bahr, S. J., Hoffmann, J. P., \& Yang, X. (2005). Parental and Peer Influences on the Risk of Adolescent Drug Use. Journal of Primary Prevention, 26(6), 529-551. https://doi.org/10.1007/s10935-005-0014-8

Beckerleg, S. (2006). What harm? Kenyan and Ugandan perspectives on khat. African Affairs, 105(419), 219-241. https://doi.org/10.1093/afraf/adi105

Cheloti, S. K., \& Gathumbi, A. M. (2016). Curbing drug and substance abuse in secondary schools in Kenya; the disconnect in school community intervention strategies. Retrieved from http://repository.seku.ac.ke/handle/123456789/2604 
Dahoma, M. J., Salim, A., Abdool, R., Othman, A., Makame, H., Ali, A. S. (2006). HIV and substance abuse: the dual epidemics challenging Zanzibar. African Journal of Drug and Alcohol Studies, 5(2), 129-38.

David M. Ndetei MBChB, C. in P. (Lond), DPM, MRCPsych, FRCPsych, MD, Lincoln I. Khasakhala MBChB, M., BA, V. M., Francisca A. Ongecha-Owuor MBChB, Mm. P., \& Donald A. Kokonya MBChB, Mm. P. (2009). Patterns of Drug Abuse in Public Secondary Schools in Kenya. Substance Abuse, 30(1), 69-78. https://doi.org/10.1080/08897070802606436

Dimova, M. (2016). “The first dragon to slay": unpacking Kenya's war on drugs. Review of African Political Economy, 43(148), 227-242. https://doi.org/10.1080/03056244.2016.1169165

Kandel, D. B., Kessler, R. C., \& Margulies, R. Z. (1978). Antecedents of adolescent initiation into stages of drug use: A developmental analysis. Journal of Youth and Adolescence, 7(1), 13-40. https://doi.org/10.1007/BF01538684

Kinoti, K. E., Jason, L. A., \& Harper, G. W. (2011). Determinants of Alcohol, Khat, and Bhang Use in Rural Kenya. African Journal of Drug and Alcohol Studies, 10(2), 107-118.

Marais, P., \& Maithya, R. (2015). Strategies for prevention and intervention of drug abuse among students in secondary schools in Kenya. Africa Education Review, 12(2), 193-210. https://doi.org/10.1080/18146627.2015.1107978

Mrug, S., Gaines J., Su W., and Windle M. (2010). School-Level Substance Use: Effects on Early Adolescents' Alcohol, Tobacco, and Marijuana Use. Journal of studies on Alcohol and Drugs, V01. 71(4): 488-495.

Schaefer, B. P., Vito, A. G., Marcum, C. D., Higgins, G. E., \& Ricketts, M. L. (2015). Examining Adolescent Cocaine Use with Social Learning and Self-Control Theories. Deviant Behavior, 36(10), 823-833. https://doi.org/10.1080/01639625.2014.977178

Syvertsen, J. L., Ohaga, S., Agot, K., Dimova, M., Guise, A., Rhodes, T., \& Wagner, K. D. (2016). An ethnographic exploration of drug markets in Kisumu, Kenya. International Journal of Drug Policy, 30, 82-90. https://doi.org/10.1016/j.drugpo.2016.01.001

The History of NACADA: An Amazing Journey. (2009). NACADA Journal, 29(2), 41-55. https://doi.org/10.12930/0271-9517-29.2.41

Weinberg, N. Z., Rahdert, E., Colliver, J. D., \& Glantz, M. D. (1998). Adolescent Substance Abuse: A Review of the Past 10 Years. Journal of the American Academy of Child \& Adolescent Psychiatry, 37(3), 252-261. https://doi.org/10.1097/00004583199803000-00009

Wills, T. A., Sandy, J. M. and Yaeger, A. M. (2001). Coping dimensions, life stress, and adolescent substance use: A latent growth analysis, Journal of Abnormal Psychology, 110:309-23. 


\section{Theses}

Karega, M. (2012). Relationship Between Perceived Parental Nurture and Problem Behaviour Among Secondary School Students in Kenya. Unpublished PhD thesis, Kenyatta University, Kenya.

Maithya, R. W. (2009, November). Drug abuse in the secondary school in Kenya: developing a programme for prevention and intervention (Thesis). Retrieved from http://uir.unisa.ac.za/handle/10500/3433

Muigai, J. W. (2012). Male youth predisposition to drug and substance abuse in Dagoretti District, Nairobi County (Thesis). University of Nairobi, Kenya. Retrieved from http://erepository.uonbi.ac.ke:8080/xmlui/handle/11295/9655

\section{Books}

Blum, R. H. (1972). Horatio Alger's children: The role of the family in the origin and prevention of drug risk. Jossey-Bass.

Gross, R. (2016). Psychology: The Science of Mind \& Behaviour; Seventh Edition. Hodder Education. $\quad$ Retrieved from http://125.234.102.150:8080/dspace/handle/DNULIB 52011/7670

NACADA (2012). Report: Rapid situation assessment of the status of drug and substance abuse in Kenya. NACADA, Nairobi.

NACADA (2007). Report: Rapid situation assessment of drug and substance abuse in Kenya. NACADA, Nairobi.

Nations, U., \& Crime, U. N. O. on D. an/d. (2010). World Drug Report 2010. United Nations Publications.

Organization, W. H. (2014). Global Status Report on Alcohol and Health, 2014. World Health Organization.

Shoemaker, D. J. (2010). Theories of Delinquency: An Examination of Explanations of Delinquent Behavior. Oxford University Press, USA. Singleton Jr., R. A., Straits, B. C., \& Straits, M. M. (1993). Approaches to social research, 2nd ed (Vol. xx). New York, NY, US: Oxford University Press. 

will be applied to their work. Under the terms of this license, no permission is required from the author(s) or publisher for members of the community to copy, distribute, transmit or adapt the article content, providing a proper, prominent and unambiguous attribution to the authors in a manner that makes clear that the materials are being reused under permission of a Creative Commons License. Views, opinions and conclusions expressed in this research article are views, opinions and conclusions of the author(s). Open Access Publishing Group and European Journal of Education Studies shall not be responsible or answerable for any loss, damage or liability caused in relation to/arising out of conflicts of interest, copyright violations and inappropriate or inaccurate use of any kind content related or integrated into the research work. All the published works are meeting the Open Access Publishing requirements and can be freely accessed, shared, modified, distributed and used in educational, commercial and non-commercial purposes under a Creative Commons Attribution 4.0 International License (CC BY 4.0). 